\title{
ESTADO DEMOCRÁTICO DE DIREITO E POLÍTICAS PÚBLICAS: ESTATAL É NECESSARIAMENTE PÚBLICO?
}

\author{
Ana Monteiro \\ Cecília Coimbra \\ Universidade Federal Fluminense \\ Manoel Mendonça Filho \\ Universidade Federal de Sergipe
}

\begin{abstract}
RESUMO: O presente texto tem como cenário o "apartheid social contemporâneo" que caracteriza a sociedade de controle globalizado onde, apesar da precarização do mercado de trabalho, difunde-se cada vez mais a subjetividade do trabalho formal como a verdadeira natureza do homem. Nesta perspectiva, o "cidadão humano" é aquele que se vincula, rápida e prontamente, à lógica capitalista. Neste contexto, coloca-se em análise o que significam as políticas públicas formuladas e implementadas por este Estado capitalista. Para tal, apresenta-se um pequeno histórico do mito do Estado Democrático de Direito no Brasil, em especial, a partir dos chamados novos movimentos sociais que emergem na segunda metade dos anos de 1970 e por toda a década seguinte. Utilizando-se da perspectiva foucaultiana que se contrapõe aos postulados tradicionais da esquerda, pensa-se o poder como relação de forças imanentes materializadas em práticas, técnicas e disciplinas, diversas e dispersas, presentes em todo o campo social, envolvendo igualmente dominadores e dominados. A partir daí, parte-se para a afirmação de práticas publicizantes que necessariamente não precisam estar vinculadas ao Estado; de direitos construídos na experiência concreta dos homens, de suas lutas, e não do Homem idealizado, de direitos idealizados. Parte-se, enfim, para repensar a relação entre Estado e políticas públicas.
\end{abstract}

PALAVRAS-CHAVE: subjetividades capitalísticas; Estado capitalista; políticas públicas.

\section{DEMOCRATIC RULE OF LAW AND PUBLIC POLICIES: DOES STATE-OWNED NECESSARILY MEAN PUBLIC?}

\begin{abstract}
The present work is set in a scenario of "contemporary social apartheid" which represents the society of global control where, despite the growth of precarious work conditions, the subjectivities of formal work are more and more preached as being the true nature of man. From this perspective, the "human citizen" is one that fast and readily relates him or herself to the capitalistic logic. In this context, the meaning of public policies made and implemented by that State is considered. For that purpose, a brief history of the myth of the Democratic Rule of Law in Brazil is presented with an emphasis starting on those considered the new social movements that emerge in the second half of 1970's and throughout the whole following decade. Employing the perspective of Foucault, opposing to the traditional postulates of the Left, power is thought of as the relation of immanent forces materialized as diverse and scattered practices and techniques acting on the whole social field, over dominant and dominated equally. From this point, one moves towards the affirmation of publicizing practices not necessarily linked to the State; of rights constituted in the concrete experience of men, their struggle, rather than of Ideal Man, of idealized rights. At last, one moves towards rethinking the relation between the State and its public policies.
\end{abstract}

KEYWORDS: capitalistic subjectivities; capitalist State; public policies.

A questão central desenvolvida neste texto foi apresentada por um dos autores, em duas mesas redondas sobre "Psicologia e Políticas Públicas". ${ }^{1} \mathrm{Na}$ verdade, tais apresentações expressaram publicamente algumas idéias que vinham sendo trabalhadas pelos três autores em vários encontros no decorrer dos últimos anos. Quando da solicitação para a publicação, o trabalho foi intensificado, resultando neste texto produzido a seis mãos. Difícil tarefa essa de produzir encontros, nesta estranha liberdade de um mundo cada vez mais individualista, produto e produtor de confinamentos os mais variados, que se engendram em meio aos "avanços" comunicacionais. Mas, como diz o filósofo, "é ao nível de cada tentativa que se avalia a capacidade de resistência ou, ao contrário, a submissão a um controle" (Deleuze, 1992, p.218).

\section{O Apartheid Social Contemporâneo}

Corre-corre de mulheres com avisos de "homem entrando, homem entrando". O trabalho no sistema prisional no nordeste brasileiro ${ }^{2}$ tem colocado algumas questões sobre as relações nestes estabelecimentos. As precauções e preconceitos para a aproximação inicial com o campo foram surpreendidos pelo dia a dia de cortiço de um emblemático caso de presídio feminino: mulheres lavando roupa, fazendo as unhas umas das 
outras, pequenos cantos com algo de cozinha e o rumor de fundo dos fuxicos e conversas. Falas carregadas de jargões cristãos e faces conformadas. Por trás deste esboço de vida comunitária, se vê a frieza das grades do Estado: emerge a imagem de um coletivo de vidas aprisionadas.

Oriundas de pequenas localidades do interior ou da periferia da capital do estado, mais de dois terços das mulheres recolhidas ao presídio "caíram" acusadas de crimes contra o patrimônio de pequeníssima monta (frascos e perfumes, varal de roupas do vizinho, peças de roupa em lojas de departamento, objetos em "casas de família") ou transportando pequenas quantidades de maconha (nenhum caso de outro tipo de entorpecente), em geral pertencentes a um companheiro ou amigo.

Histórias de vidas muito parecidas com as que se encontraria em ocupações de baixa remuneração, como trabalho doméstico, balcão de lojas ou serviços em supermercados, os mesmos níveis de escolarização e sem antecedentes criminais. Pinçadas do segmento mais abrangente da população que estes indicadores caracterizam, são corpos raptados por uma ação policial viciada por critérios “técnicos" bem fixados, que marcam a escolha dos pontos onde efetuar as batidas e a quem se destina tal ação de captura.

Não por acaso, a população carcerária no Brasil dobrou entre os anos de 1995 e 2005. No meio da década de 1990, havia 148.760 detentos. Hoje, segundo fontes do próprio Ministério da Justiça, ${ }^{3}$ existem 262.710 condenados cumprindo pena, sendo $95 \%$ do sexo masculino e $5 \%$ do feminino. O total de estabelecimentos penais no Brasil é de 917 unidades. Segundo matéria da Folha de São Paulo (2004, p.c-1), o déficit de vagas no sistema penitenciário é maior que a lotação do estádio do Maracanã (122 mil pessoas). O Brasil tem a segunda maior população carcerária da América, com 187,7 presos para cada 100 mil habitantes, só sendo ultrapassado pelos Estados Unidos que têm 740 para cada 100 mil habitantes. A população carcerária brasileira é formada fundamentalmente por homens jovens (na faixa de 18 a 26 anos), negros ou pardos e com baixa escolaridade. ${ }^{4}$ Este é o mesmo perfil que vem sendo alvo da violência policial no Brasil.

É a memória de tempos não materialmente vividos que impõe uma imagem. Tudo funciona como uma atualização das senzalas; há, entretanto, um perverso recrudescimento. O aprisionamento nas senzalas mostrou, historicamente, um enorme potencial de vinculação coletivocomunitária, capaz de re-arranjar a convivência de membros de diferentes tribos e nações africanas em uma trama social cuja coesão criativa permitiu, não apenas a sobrevivência dos individuados corpos ali cativos, mas a permanência de valores culturais que matizam hoje muito fortemente o imaginário nacional. Em contrapartida, na atualidade, as vidas aprisionadas se caracterizam pela dificuldade de conjunção e organização, tendendo, muitas vezes, a repetir a mesma lógica da organização social que as colocou ali.

Ainda que se diga que a finalidade de socialização pelo trabalho encontra-se presente nos presídios e em vários outros equipamentos sociais, como estava nas senzalas não esqueçamos o lado salvacionista da justificativa escravocrata de transformação de primitivos preguiçosos em cristãos produtivos -, o que caracteriza as iniciativas de trabalho, como, por exemplo, para internos de presídios, são formatos de programas-piloto, que não alcançam a casa dos $10 \%$ (quando muito) e que não resistem mais que o período de uma gestão política. O cuidado com que são montados e divulgados como se tivessem uma abrangência, que de modo algum poderiam pleitear, faz pensar que as iniciativas de "re-socialização pelo trabalho" são "fachadas" destinadas a fazer crer nas boas intenções do Estado com suas políticas pretensamente públicas.

A implantação de programas de trabalho, tal como hoje se articula, poderia levar as análises a uma crítica da eficiência dos gestores ou algo que o valha. Entretanto, pelo tempo que ocupa nos discursos gestores e pelos esforços em difundir informações sobre o sucesso de implementação de tais programas faz suspeitar de outra coisa. A pista veio da fala de um gestor de presídio de segundo escalão:

é uma sinuca de bico esse negócio de reabilitação pelo trabalho com tanto desemprego. Se dentro dos presídios a coisa funcionasse ia ter gente cometendo crime para ter chance de ingressar no programa.

Ora, é a efetividade da idéia instituída de re-socia-lização pelo trabalho, que continua atrelando trabalho a emprego, que fica paradoxal em uma sociedade em que "os dias de pleno emprego estão contados", como afirma o Grupo Krisis (2003, p.11). Vale dizer "desemprego estrutural", esta noção cunhada pelas ciências sociais para falar da contínua redução dos postos de trabalho, característica da articulação da automatização da produção com o capitalismo financeiro, o que não é nenhuma novidade.

Em contraste com a redução contínua dos postos de trabalho e com as lutas sindicais e reivindicações liberais de redução generalizada das jornadas de trabalho - o que sinaliza uma admissão formal da irreversibilidade do processo de precarização do "mercado de trabalho", difunde-se cada vez mais a idéia de que o trabalho formal é a verdadeira natureza do homem. Ter um emprego passa a ser fator de "saúde mental", como sugerem as teorizações sobre o "sofrimento humano nas organizações". Ainda havemos de pagar por um posto de trabalho: esta é a imagem calvinista, dominante no contemporâneo, de um sujeito de pura vontade e consciência.

Diferentes teorias organizacionais formulam explicações de como os ganhos secundários gerados pelo reconhe- 
cimento da finalização de etapas de produção sustentam a "saúde mental do trabalhador". Programas institucionais de formação continuada animam grandes segmentos da população a investirem em sua qualificação para o trabalho, e nas escolas e universidades o norte da formação é dado pelas expectativas voltadas para o "mercado de trabalho formal”, como se este fosse o único caminho. Ter ou não um emprego, estar ou não de algum modo vinculado ao sistema de produção do capitalismo mundial integrado é o indicador do estatuto de humano, mais ou menos e, como nunca, demasiadamente humano: "hoje quem não consegue vender sua força de trabalho é considerado supérfluo e é jogado no aterro sanitário social" (Grupo Krisis, 2003, p.16).

Nesta perspectiva, o cidadão humano passa a ser considerado como aquele que se vincula, rápida e prontamente, à lógica capitalística. Tal vinculação se faz de diferentes modos: pela ocupação das poucas posições dos iluminados controladores dos processos de mercado, "os que pertencem à irmandade dos ganhadores globais com seus sorrisos cínicos" (Grupo Krisis, 2003, pp.19-20); pela conexão ao movimento acelerado dos fluxos de capitais, que acaba por lançar uma parcela dos humanos nas fileiras, cada vez menores, dos gerentes operadores dos processos de produção e prestação de serviços. Emergentes sociais, ajuntamento de homens nada livres, que exercem suas funções de capatazes procurando afirmar uma distância entre suas pseudo-identidades sustentadas por uma coleção de etiquetas que atestariam sua vinculação com o primeiro grupo (carros e roupas de marca, carteiras de trabalho provisoriamente assinadas, cartões de crédito limitados e títulos profissionais legalmente reconhecidos). Esforçando-se para permanecer na órbita do mercado, não se percebem como estando nas bordas e, continuamente, ameaçados pela, cada vez maior, precariedade dos vínculos formais de trabalho. A estes que aí estão, incluídos na ameaça contínua de ex-clusão de fato ou em potencial, "só resta uma função social: a de ser o exemplo aterrorizante. Precisam aceitar qualquer trabalho, qualquer programa de ocupação, mesmo o mais absurdo (...)" (Grupo Krisis, 2003, p.25). Há, ainda, um terceiro e importante grupo, constituído pelas grandes massas populacionais, que embora já tenha espirrado das bordas, permanece vinculado à mesma lógica de mercado, buscando a todo custo usufruir dos prazeres consumistas.

O sistema que os grupos acima mencionados conformam é o que se pode chamar de sociedade globalizada de controle: tudo e todos incluídos na lógica capitalística, marcados profundamente pelo modo indivíduo de subjetivação que afirma o consumo e a ascensão social como pré-requisitos de humanidade.

Os assim chamados dispositivos de inclusão social estão mais para a face perversa do paradoxo de uma forma de organização social que afirma uma impossibilidade como condição de pertença: preparar-se crédula e desesperadamente para aquilo que já não existe como possibilidade, o trabalho formalizado em emprego. Efeitos de produção de subjetividade pela via da culpabilização individual: quem não consegue um trabalho formal "é por si próprio culpado e pode ser proscrito ou até mesmo descartado com boa consciência" (Grupo Krisis, 2003, p.17). A culpabilização é uma função da subjetividade capitalística. As tecnologias de culpabi-lização se assentam sempre na busca de imagens modelares de referência (Guattari, 1986).

O caráter paradoxal da dificuldade encontrado em muitas intervenções, como aquelas realizadas em presídios, por exemplo, aparece no fato de que, mesmo com a experiência da violência do Estado em sua forma mais explícita, se mantém a aspiração pelo trabalho formal que é dito livre, por uma vida dita cidadã, atrelada às ordens do mercado, como se isso fosse possível, algo que decididamente não é destinado, em especial, àqueles que espirraram da borda.

É no espaço dos que estão na borda e dos que dela espirraram que "funcionam" os serviços que executam as políticas públicas formuladas pelos gestores atrelados ao Estado: a rede pública de educação, o sistema público de saúde e o aparelho de re-socialização do sistema prisional, dentre outros, cada um respectivamente destinado conforme a pretensão por serviços ou produtos que almeje o desqualificado candidato. Complementares das funções operados por esses serviços, "o incomodo do lixo humano fica sob a competência do Estado policial, das seitas religiosas (e/ou político-partidárias) de salvação (...)" (Grupo Krisis, 2003, p.20), do trabalho voluntário também produzido como salvação e de muitos "abnegados" funcionários públicos - crédulos nas políticas públicas formuladas e implementadas pelo Estado - com seus salários garantidos cada vez menores.

Eis o cenário onde a alegria da vida plena de sentido se transforma em busca individual de significado, significado isolado, que só emana da raiz tronco modulada por uma gramática regulamentada. Neste ponto, parece que a alternativa é encontrar uma missão, dedicar-se a ela compulsivamente, trabalhar com afinco em seu encargo, sem deixar que nada interfira, pura motivação apaixonada pela obsessão de uma produção que não consegue se diferenciar da produtividade requerida pelo mercado. Para este funcionamento sujeito - ou para este modo de produção de subjetividade, se se preferir -, fora do absoluto de sua missão, tudo parece vazio.

Entenda-se aqui por funcionários os agentes direta ou indiretamente encarregados pela operacionalização das funções de Estado, não importando o grau de formalização institucional de seu estatuto de funcionário público. Estado 
este que, cada vez mais, amplia sua função policialrepressiva, transformando-se em Estado Penal que, em nome da vida, encarcera e deixa morrer todas as expressões de vida consideradas improdutivas e impróprias. E quais são as funções reservadas ao Estado senão as de garantir a segurança necessária para o bom funcionamento do capitalismo de mercado?

Há mais ou menos 30 anos, Michel Foucault afirmou que não se trata mais de colocar questões sobre o poder partindo de um modelo jurídico. Introduzindo o termo "biopolítica", distingue o poder de soberania, como modo centralizado/transcendente de exercício do poder, de um tipo de poder que define como biopoder: poder de produzir e transformar a própria vida na imanência do capital. Trata-se de um poder-saber que, através de discursos e práticas, produz realidades subjetivas e objetivas, e na medida em que se difunde, fabrica os humanos e a sociedade pela separação daqueles que podem/devem viver daqueles para os quais basta deixar morrer. Encarregado da gestão calculista da vida, esse poder passa a operar tanto na via das ordenaçõos disciplinares dos corpos, como na via da produção e controle da vida em seu conjunto. Se antes o poder soberano operava sobre o direito de fazer morrer ou de deixar viver, com o desenvolvimento do capitalismo, ocorre "uma das mais maciças transformações do direito político, que, na verdade, vem a complementar o velho direito de soberania com outro direito, ou melhor, um poder exatamente inverso: poder de fazer viver e de deixar morrer" (Foucault, 2000, p.287).

Entendendo que é essa lógica de poder difuso sobre a vida que está presente em nosso cotidiano, passamos a interrogar a produção do mito do Estado Democrático de Direito, onde as noções de público e comum aparecem naturalmente associadas às ações do Estado: o que se entende por Estado Democrático de Direito em termos de práticas e implementação de políticas públicas? Estatal é necessariamente público?

\section{O Mito do Estado Democrático de Direito no Brasil}

$\mathrm{Na}$ segunda metade dos anos 1970 e nos anos 1980, emergem, na luta contra a ditadura militar no Brasil, diferentes movimentos sociais que se diferenciam dos anteriores que se expressaram um pouco antes e logo após o golpe de 1964. Tais movimentos vêm no bojo de três grandes frentes de luta contra a ditadura: a Igreja, com a Teologia de Libertação, que implementa as comunidades eclesiais de base; a política partidária, com a inclusão das questões cotidianas, que acabam por organizar associações de bairros, moradores, reformas na saúde e na educação, movimentos feministas, negros, gays, etc; o sindicalismo, com as comissões de fábricas, movimentos grevistas, que culminaram com a criação do Partido dos Trabalhadores (Sader, 1992).

Os movimentos sociais deste período não são espontâneos, mas fazem parte de toda uma estratégia coletiva de resistência. É a luta por liberdades democráticas, pela conquista de espaços, de canais de abertura a expressões e valores diferentes dos impostos pelos porta-vozes do capitalismo internacional via ditadura militar. Embora marcados pela lógica da representação partidária, inauguram um outro modo de pensar e fazer política. Ao enfatizar o cotidiano, o pequeno, o invisível, o capilar, a política vai se expressando positivamente nesta dimensão microfísica que antes era desconsiderada pelos movimentos de resistência. No entanto, no processo é a dimensão macro, com seus lugares de poder estabelecidos pela lógica da representação partidária que vai sendo privilegiada: o da conquista de um lugar de poder que se acreditava estar localizado no Estado.

Há aí uma concepção de poder que vem, desde essa época, dando sustentação a essas lutas de resistência: lugares, centros de poder que continuam mantidos pela lógica da representação, de um poder ao mesmo tempo transcendente e reificado. Vale lembrar que, no Brasil, devido ao contexto autoritário, a luta se fez tendo como meta a conquista de um Estado Democrático de Direito, já que esta via aparecia como única possibilidade de enfrentamento dos poderes estabelecidos naquele momento. Não se percebeu que, neste mesmo período, novos modos de dominação global se impunham numa versão mais sutil: a ditadura de mercado.

Como assinalamos no inicio do texto, já nos anos 1970, Michel Foucault (1977) desenvolve em seu livro Vigiar e Punir uma análise crítica sobre estes postulados tradicionais do pensamento de esquerda. Para ele, esta ilusão se funda a partir de um entendimento que pensa o poder como "propriedade de uma classe" que o teria conquistado, como uma essência ou atributo e/ou como encarnado no aparelho de Estado, subordinado a um modo de produção. Foucault, contrapondo-se a estes postulados, vai pensar o poder como relação de forças imanentes materializadas em práticas, técnicas e disciplinas, diversas e dispersas, presentes em todo o campo social, envolvendo igualmente dominadores e dominados. Assim, o aspecto privilegiado pelo pensador em sua análise se concentra não no poder, mas nos efeitos da relação saber/poder relativos ao modo individualizante de subjetivação. Ou seja, uma analítica do poder/saber que emerge como analítica de uma determinada experiência subjetiva que configura um "próprio de si" que busca o privado, aspira por ele e conspira contra o público: um fechamento que faz 
emergir um outro tipo de centralidade, encarnada privilegiadamente em cada indivíduo, cada vez mais separado da coletividade, da experiência publicizante.

Temos, assim, para grande parte dos movimentos sociais no Brasil, uma configuração onde persiste a lógica dos lugares de poder e dos detentores de poder, como se com o desenvolvimento do capitalismo o poder não se exercesse em qualquer lugar, em todos os lugares cada vez mais de forma imanente, tendo no capital a expressão de força auto-produtiva dispersa por todo o tecido social. A hegemonia que produz efeitos de dominação provém desta lógica. Nesse funcionamento imanente da máquina capitalística, pautado pela lógica dominado/dominador, disseminam-se formas de produzir capital de maneira licita ou ilícita, ampliando sua produção indefinidamente: mais capital, mais poder, mais produção de um determinado modo de viver - voltado para defender o EU, o Meu patrimônio individual, a Minha verdade privada, mesmo que seja em grupos, partidos, sindicatos ou empresas vinculados explicitamente ou não ao Estado.

É verdade que novas experiências surgiram na luta pelas liberdades democráticas durante o período de fechamento ditatorial no Brasil. Tratava-se de uma abertura, sem dúvida: forças coletivas forçando novas formas de expressão. No entanto, na desconsideração aos novos modos de dominar, a lógica de lugares dominado/dominador -, que alimenta tradicionalmente o exercício do poder, permanece intocada. Busca-se ocupar estes lugares de poder na suposição de poder assim possuir o poder. Ter poder, vontade de poder, vontade de dominar. Há aí uma ilusão de que se possa possuir o poder de Estado para usá-lo de uma outra maneira. Persiste aí a idéia de representação: vanguardas, salvadores, pastores identificados com a causa do bem maior, porque oriundos do lugar de dominados.

$\mathrm{O}$ que fica obliterado por este esquema de entendimento é a idéia de que um lugar de poder instituído, como o aparelho de Estado, funciona segundo certas lógicas, e que "ocupá-lo" é, na maior parte das vezes, servi-lo na condição de operador de seus dispositivos e, nesta condição, o operador não muda a máquina, ele a faz funcionar. Experimentando a impossibilidade de transformar o funcionamento das máquinas estatais capitalisticas, mantém-se a crença na possibilidade de reformas através de intervenções nas formulações e implementações de políticas públicas vinculadas ao Estado. Estas "Ilusões Re"” encontram-se hoje presentes em muitas áreas de intervenção: no campo da educação, saúde, justiça, etc.

\section{Do Estado Democrático à Invenção/Afirmação de Práticas Publicizantes}

Compartilhamos com Saramago (2005), quando, no Fórum Social Mundial, defende a idéia de que não devemos nos limitar simplesmente a reivindicar um outro mundo possível. Em lugar de pôr este desejo num futuro, que se apresenta como um objetivo a alcançar, é necessário que o "tal mundo possível” não fique, enfim, para não se sabe que tempo e para não se sabe que lugar. Que seja afirmado na invenção/experimentação de caminhos que se fazem no próprio ato de caminhar, para não repetirmos as nossas boas e justas razões infinitamente. Diz ele:

A utopia é alguma coisa que não se sabe onde está. O próprio termo está a dizê-lo: U e topos. Portanto, algo que se supõe que existe, mas não se sabe onde está (...). O que pode ter alguma importância é a ação contínua. Esta, se quer que lhe diga, é a minha utopia (Saramago, 2005).

Saramago (2005) analisa as concepções correntes de utopia e democracia. Na utopia coloca-se no futuro a possibilidade do hoje. Em relação à democracia, toma-se como algo cristalizado, um Estado definitivo, "como uma santa a ser adorada no altar”. Pergunta então: "Quem nos garante que as pessoas no futuro estarão interessadas naquilo que hoje eu estou interessado?" Sendo assim, o importante é viver as experiências no dia a dia, pois a palavra que hoje tem um sentido, não terá o mesmo amanhã. E finaliza: "As ações hoje devem ser diretas e imediatas, pois aquilo que dizemos ser possível nesse momento é, em realidade, uma prática de resignação".

Entendemos assim que, para escaparmos da ilusão do Estado Democrático de Direito com suas práticas de resignação, a questão dos direitos deve ser colocada num "plano comum": direitos construídos na experiência concreta dos homens, de suas lutas e não do Homem idealizado, de direitos idealizados. "Um homem em processo contínuo de humanização" (Barros \& Passos, 2005, p.569), de novos sujeitos implicados em práticas que engendram novos modos de subjetivação.

Para tanto, há que repensar a relação entre Estado e políticas públicas. Acreditamos que estes termos não podem ser tomados como coincidentes, visto que os domínios do Estado e do público não se justapõem, não sendo natural a relação de sinonímia entre eles. Entendemos que o público diz respeito à experiência concreta dos coletivos de forças sempre em movimento. Daí estar em um plano diferente daquele do Estado enquanto figura paralisada e transcendente da modernidade.

Apostamos que o plano do público só pode ser construído a partir das experiências de cada homem inserido na coletividade, na imanência de uma humanidade que se define não a partir de um conceito abstrato de Homem. 
Neste sentido, não havendo uma imagem definitiva e ideal d'O Homem, só nos resta aceitar a tarefa sempre inconclusa da reinvenção de nossa humanidade, o que não se pode fazer sem o trabalho também constante da produção de outros modos de vida, de novas práticas (...) (Barros \& Passos, 2005, p.570).

Trabalho este que só se consegue quando nos encontrarmos e nos percebemos como forças enredadas coletivamente. É aí que nos produzimos na criação de redes afetivas e parcerias amorosas, capazes de ligar o singular ao múltiplo.

Concluímos, então, com a força de algumas interrogações. O que nos leva a permanecer conectados ao mito da democracia representativa, às forças reativas e ao ressentimento ao invés de afirmarmos a força dos micromovimentos inventivos que eclodem o tempo todo em nosso cotidiano? Como pensar políticas públicas não mais reduzidas ao Estado, mas como afirmação de experiências diversas onde o público possa, de fato, ser a expressão da experiência do "comum" que faz advir outros e múltiplos modos de pensar, perceber, sentir, agir e viver?

Carregamos no peito, cada um, batalhas incontáveis. Somos a memória perigosa das lutas.

Projetamos a perigosa imagem do sonho.

Nada causa mais horror à ordem do que homens e mulheres que sonham.

Nós sonhamos...

A revolução que acalentamos na juventude faltou.

A vida não.

A Vida não falta.

E não há nada mais revolucionário que a Vida.

... Aprendemos que a construção deste país não será obra apenas de nossas mãos.

Nosso retrato futuro resultará da desencontrada multiplicação dos sonhos que desatamos (Tierra, 1994).

\section{Notas}

1. Mesas organizadas pelos Conselhos Regionais de Psicologia do Rio Grande do Sul, Rio de Janeiro e Minas Gerais no IV Congresso Norte-Nordeste de Psicologia, em maio de 2005 e no I Congresso Latino-Americano de Psicologia (ULAPSI), em abril de 2005 com a participação de Cecília Coimbra.

2. Trabalho de pesquisa que vem sendo desenvolvido pelo Prof. Manoel Mendonça Filho no Presídio Estadual de Sergipe através do GEPEC/UFS com apoio do CNPq.

3. www.ministeriodajustiça.gov.br

4. Segundo fontes oficiais, somente $20 \%$ dos presos têm mais que 5 anos de escolaridade.

5. Termo utilizado por Batista (2005).

6. Segundo Pelbart (2003), "há hoje um seqüestro do comum, uma expropriação do comum, ou uma manipulação do comum, sob formas consensuais unitárias, espetacularizadas, totalizadas, trans-cendentalizadas... (É fundamental) descobrirmos comunidade lá onde não se via comunidade, e não necessariamente reconhecer comunidade lá onde todos vêem comunidade, não por um gosto de ser esquisito, mas por uma ética que contemple também a esquisitice e as linhas de fuga, novos desejos de comunidade emergentes, novas formas de associar-se e dissociarse que estão surgindo, nos contextos mais auspiciosos ou desesperadores" (p. 28; p.41).

\section{Referências}

Barros, R. \& Passos, E. (2005).A humanização como dimensão pública das políticas de saúde. Ciência e Saúde Coletiva, 10(3),561-571.

Batista, V.M.B. (2005, outubro). Sistema Prisional no Rio de Janeiro. Trabalho apresentado no Conselho Regional de Psicologia/ Rio de Janeiro, no $1^{\circ}$ Encontro Regional dos Psicólogos do Sistema Prisional do Rio de Janeiro (Material não-publicado).

Deleuze, G. (1992). Conversações. Rio de Janeiro: Ed.34.

Escóssia, F. (2005). Sistema Prisional no Brasil. Jornal Folha de São Paulo, 10/07/2004.

Foucault, M. (1977). Vigiar e Punir. Rio de Janeiro: Vozes.

Foucault, M. (2000). Em defesa da sociedade: curso no Collège de France (1975-1976). São Paulo: Martins Fontes.

Grupo Krisis (2003). Manifesto contra o trabalho. São Paulo: Conrad Editora do Brasil (Coleção Baderna).

Guatari, F. (1986). Micropolítica: cartografias do desejo. Petrópolis, RJ: Vozes.

Negri, A. \& Hardt, M. (2001). Império. Rio de Janeiro: Record.

Pelbart, P. (2003). Vida capital: ensaios de Biopolítica. São Paulo: Iluminuras.

Sader, E. (2005). Quando novos personagens entraram em cena. São Paulo: Paz e Terra.

Tierra, P. (1994). Os Filhos da Paixão. Poesia apresentada no $8^{\circ}$ Encontro Nacional do PT. (Material não publicado).

Ana Monteiro é Médica e Analista; Supervisora do Projeto de Acompanhamento Terapêutico na Universidade Federal Fluminense; Mestre em Psicologia pela Universidade Federal Fluminense. ana monteiro@uol.com.br

Cecília Coimbra é Psicóloga, Professora Adjunta da Universidade Federal Fluminense, Doutora em

Psicologia pela Universidade de São Paulo; Vice-Presidente do Grupo Tortura Nunca Mais/RJ e Conselheira do Conselho Regional de Psicologia do Rio de Janeiro. O endereço para correspondência

com o autor é: Praia de Botafogo, 22, apt ${ }^{\circ} 502-$ Botafogo, 22250-014 - Rio de Janeiro, RJ.

gtnm@alternex.com.br

Manoel Mendonça Filho é psicólogo, Professor Adjunto da Universidade Federal de Sergipe, Doutor em Psicologia pela Universidade Federal da Bahia.

mendoncafilho@ufs.br

\section{Estado democrático de direito e políticas públicas: estatal é necessariamente público?}

Ana Monteiro, Cecília Coimbra e Manoel Mendonça Filho Recebido: 03/11/2005

$1^{\text {a }}$ revisão: 15/02/2006

Aceite final: 10/05/2006 